\title{
Quantitation of CXCR4 Expression in Myocardial Infarction Using ${ }^{99 \mathrm{~m} T c-L a b e l e d ~ S D F-1} \alpha$
}

Preeti Misra ${ }^{1}$, Djamel Lebeche ${ }^{2}$, Hung Ly², Martina Schwarzkopf ${ }^{2}$, George Diaz ${ }^{3}$, Roger J. Hajjar ${ }^{2}$, Alison D. Schecter ${ }^{2,4}$, and John V. Frangioni ${ }^{1,5}$

\begin{abstract}
${ }^{I}$ Division of Hematology/Oncology, Beth Israel Deaconess Medical Center, Boston, Massachusetts; ${ }^{2}$ The Cardiovascular Research Center, Mount Sinai School of Medicine, New York, New York; ${ }^{3}$ Department of Human Genetics, Mount Sinai School of Medicine, New York, New York; ${ }^{4}$ Departments of Medicine and Immunobiology, Mount Sinai School of Medicine, New York, New York; and ${ }^{5}$ Department of Radiology, Beth Israel Deaconess Medical Center, Boston, Massachusetts
\end{abstract}

The chemokine stromal-derived factor- $1 \alpha$ (SDF-1 $\alpha$, CXCL12) and its receptor CXCR4 are implicated as key mediators of hematopoietic stem cell retention, cancer metastasis, and HIV infection. Their role in myocardial infarction (MI) is not as well defined. The noninvasive in vivo quantitation of CXCR4 expression is central to understanding its importance in these diverse processes as well in the cardiac response to injury. Methods: Recombinant SDF- $1 \alpha$ was radiolabeled under aprotic conditions and purified by gel-filtration chromatography (GFC) using high-specific-activity $99 \mathrm{mTc}-\mathrm{S}$-acetylmercaptoacetyltriserine- $N$ -

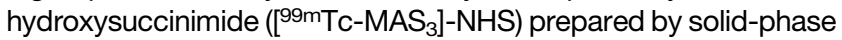
preloading. Radiotracer stability and transmetallation under harsh conditions were quantified by GFC. Affinity, specificity, and maximum number of binding sites $\left(\mathrm{B}_{\max }\right)$ were quantified, with adenoviralexpressed CXCR4 on nonexpressing cells and endogenous receptor on rat neonatal cardiomyocytes, using a high-throughput live-cell-binding assay. Blood half-life, biodistribution, and clearance of intravenously injected [ $\left.{ }^{99 m} \mathrm{Tc}^{-M_{A S}}{ }_{3}\right]-S D F-1 \alpha$ were quantified in Sprague-Dawley rats before and after experimentally induced MI. Results: [ ${ }^{99 m T c-M A S}{ }_{3}$ ]-SDF- $1 \alpha$ could be prepared in $2 \mathrm{~h}$ total with a specific activity of $8.0 \times 10^{7} \mathrm{MBq} / \mathrm{mmol}(2,166$ $\mathrm{Ci} / \mathrm{mmol}$ ) and a radiochemical purity greater than $98 \%$. Degradation of the radiotracer after boiling for $5 \mathrm{~min}$, with and without $1 \mathrm{mM}$ dithiothreitol, and transmetallation in $100 \%$ serum at $37^{\circ} \mathrm{C}$ for $4 \mathrm{~h}$ were negligible. [ $\left.{ }^{99 \mathrm{mTc}} \mathrm{MAS}_{3}\right]-\mathrm{SDF}-1 \alpha$ exhibits high specificity for CXCR4 on the surface of living rat neonatal cardiomyocytes, with an affinity of $2.7 \pm 0.9 \mathrm{nM}$ and a $B_{\max }$ of $4.8 \times 10^{4}$ binding sites per cell. After intravenous injection, $99 \mathrm{mTc}$-labeled SDF- $1 \alpha$ displays a blood half-life of $25.8 \pm 4.6 \mathrm{~min}$, rapid renal clearance with only $26.2 \pm 6.1$ percentage injected dose remaining in the carcass at $2 \mathrm{~h}$, consistently low uptake in most organs $(<0.1$ percentage injected dose per gram), and no evidence of blood-brain barrier penetration. After MI was induced, CXCR4 expression levels in the myocardium increased more than 5-fold,

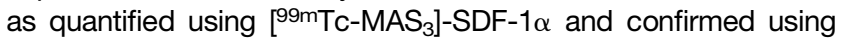
confocal immunofluorescence. Conclusion: We describe a ${ }^{99 m T c-}$ labeled SDF- $1 \alpha$ radiotracer that can be used as a sensitive and specific probe for CXCR4 expression in vivo and demonstrate

Received Dec. 18, 2007; revision accepted Feb. 28, 2008.

For correspondence or reprints contact: John V. Frangioni, Beth Israel Deaconess Medical Center, 330 Brookline Ave., Room SL-B05, Boston, MA 02215.

E-mail: jfrangio@bidmc.harvard.edu

COPYRIGHT @ 2008 by the Society of Nuclear Medicine, Inc. that this radiotracer is able to quantify changes in CXCR4 expression under different physiologic and pathologic states. Taken together, CXCR4 levels should now be quantifiable in vivo in a variety of animal model systems of human diseases.

Key Words: SDF-1 $\alpha$; CXCR4; chemokines; SPECT radiotracers; myocardial infarction

J Nucl Med 2008; 49:963-969

DOI: 10.2967/jnumed.107.050054

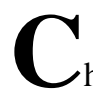
hemokines are a family of structurally related glycoproteins, ranging in size from 6 to $14 \mathrm{kDa}$, with potent leukocyte activation or chemotactic activity. They are grouped into 4 classes, CC, CXC, C, and CX3C, based on the position of the first 2 conserved cysteine residues in the mature protein (1). On the basis of its amino acid motif, stromal-derived factor-1 (SDF-1, CXCL12) belongs to the CXC class of chemokines.

SDF-1 $\alpha$ and its receptor CXCR4, an important chemokinereceptor pair, play a crucial role in numerous biologic processes including hematopoiesis, vasculogenesis, neuronal development, and immune cell trafficking (2-4). They also have been implicated in various pathologic conditions such as cancer $(5,6)$, infection with HIV (7), and various inflammatory conditions $(8,9)$.

Recently, there has been increased focus on the role of chemokines in cardiovascular development (10) and in adult cardiac disease such as acute coronary syndromes (11) and heart failure (12). Chemokines and their receptors are present and functional on the myocardium and on vascular smooth muscle cells (13) and are capable of mediating important biologic processes in a manner that is independent of inflammatory cells (14). Both SDF- $1 \alpha$ and its receptor CXCR4 are essential for cardiogenesis (15), and CXCR4 is expressed on early hematopoietic stem cells (SCs) and endothelial progenitor cells (4). SDF- $1 \alpha$ even appears to modulate myocyte contractility in rodent model systems (12). Recently, several studies have demonstrated that circulating chemokine levels, including those of SDF- $1 \alpha$, are 
elevated in animals and humans with cardiac dysfunction $(16,17)$, and both chemokines and their receptors are upregulated in the hearts of patients with congestive heart failure (18). After myocardial infarction (MI), chemokines mediate the retention of SCs that could potentially repair damaged myocardium (19), and reestablishing SDF- $1 \alpha$ expression some time after undergoing MI may restore SC homing to the damaged cardiac tissue $(20,21)$.

Although associated with cardiac dysfunction, the mechanisms by which chemokines and their receptors exert their effects are largely unknown. Because the role of chemokines in the cardiac response to inflammation may be quite distinct from that of cytokines (22), and because of the recent focus on using chemokines to modulate the SC milieu in the heart, there is an urgent need to quantify chemokine and chemokine receptor levels in vivo, noninvasively, and over time.

Our laboratory has previously developed a solid-phase preradiolabeling technique for rapid and efficient ${ }^{99 \mathrm{~m}} \mathrm{Tc}-$ labeling of small molecules and peptides under aprotic conditions (23). In the present study, we use this technique to prepare a biologically active SDF- $1 \alpha$ radiotracer with high specific activity. We also demonstrate that CXCR4 levels can now be quantified in vivo and over time and that CXCR4 is significantly overexpressed in myocardium subjected to infarction.

\section{MATERIALS AND METHODS}

\section{Reagents}

Recombinant murine SDF-1 $\alpha$ was purchased from Peprotech. The $N$-hydroxysuccinimide (NHS) ester of hydrazinonicotinamide (HYNIC) was the generous gift of Jean-Luc Vanderheyden (Theseus Imaging). Ultradry dimethylsulfoxide (DMSO) was purchased from Acros Organics; high-performance liquid chromatography (HPLC)-grade triethylammonium acetate, $\mathrm{pH} \mathrm{7,} \mathrm{was} \mathrm{obtained}$ from Glen Research; and HPLC-grade water was purchased from American Bioanalytic. All other chemicals were purchased from Fisher Scientific and were ACS- or HPLC-grade.

\section{Synthesis and Purification of [99mTc-MAS 3 -SDF-1 $\alpha$}

The NHS ester of $99 \mathrm{~m} \mathrm{Tc}-S$-acetylmercaptoacetyltriserine $\left({ }^{99} \mathrm{Tc}-\mathrm{MAS}_{3}\right)$ was prepared to high purity $(>99 \%)$ and high specific activity (average, $1.1 \times 10^{8} \mathrm{MBq} / \mathrm{mmol} ; 3 \times 10^{3} \mathrm{Ci} / \mathrm{mmol}$ ) in DMSO using a 20-min protocol described in detail previously (23). For radiolabeling, SDF-1 $\alpha$ dry powder was resuspended in DMSO at a concentration of $12.6 \mu \mathrm{M}$. A total of $185 \mathrm{MBq}(5$ $\mathrm{mCi} ; 0.45 \mathrm{nmol})$ of [ $\left.{ }^{99 \mathrm{~m}} \mathrm{Tc}-\mathrm{MAS}_{3}\right]-\mathrm{NHS}(550 \mu \mathrm{L})$ was mixed with $50 \mu \mathrm{L}(0.63 \mathrm{nmol})$ of SDF- $1 \alpha$, followed by the addition of $2 \mu \mathrm{L}$ (8 $\mu \mathrm{mol})$ of $4 \mathrm{M}$ triethylamine. Constant stirring at room temperature was maintained for $1 \mathrm{~h}$. Radiolabeled [ ${ }^{99 \mathrm{~m}} \mathrm{Tc}^{-M_{A}} \mathrm{~S}_{3}$ ]-SDF- $1 \alpha$ was purified by gel-filtration chromatography (GFC) using an $8 \times 300$ mm, 60-Å Diol (catalog number DL06S053008WT; YMC) gelfiltration column and phosphate-buffered saline (PBS), pH 7.4, as mobile phase. Details of the HPLC system and detectors have been described in detail previously (24). GFC-purified [ ${ }^{99 \mathrm{~m}} \mathrm{Tc}-$ $\mathrm{MAS}_{3}$ ]-SDF- $1 \alpha$ (specific activity, $8.0 \times 10^{7} \mathrm{MBq} / \mathrm{mmol} ; 2,166 \mathrm{Ci} /$ $\mathrm{mmol}$ ) was concentrated to $\approx 148 \mathrm{MBq} / \mathrm{mL}(4 \mathrm{mCi} / \mathrm{mL})$ using a 5,000-molecular-weight cutoff cartridge (Vivaspin; Sartorius Stedim Biotech).

\section{Synthesis of ${ }^{99 m}$ Tc-HYNIC-Albumin}

Covalent conjugation of the HYNIC-NHS to albumin was performed by mixing $1 \mathrm{~mL}(72 \mathrm{nmol})$ of a $5 \mathrm{mg} / \mathrm{mL}$ solution of Cohn Fraction V bovine serum albumin (Sigma-Aldrich) in PBS and $100 \mu \mathrm{L}(320 \mathrm{nmol})$ of $3.2 \mathrm{mM}$ HYNIC-NHS in DMSO. After incubation for $2 \mathrm{~h}$ at room temperature, unreacted ligand was removed by the GFC on a prime pump and a 10/300 GL column (ÄKTA; Amersham Biosciences and Superose-6; Amersham Biosciences) using $114 \mathrm{mM}$ tricine, $\mathrm{pH}$ 6.6, as mobile phase and a flow rate of $1 \mathrm{~mL} / \mathrm{min}$. Exchange labeling using tricine as weak ligand was performed by adding $1 \mathrm{mg}$ of tricine powder to $1 \mathrm{~mL}$ of the derivatized albumin solution, followed by $25 \mu \mathrm{g}$ of $\mathrm{SnCl}_{2} \cdot 2 \mathrm{H}_{2} \mathrm{O}$ dissolved in $12.5 \mu \mathrm{L}$ of $0.01 \mathrm{~N} \mathrm{HCl}$ and $100 \mu \mathrm{L}(185-296 \mathrm{MBq} ; 5-8$ $\mathrm{mCi}$ ) of ${ }^{99 \mathrm{~m}} \mathrm{Tc}$-pertechnetate. After a 30 -min incubation, radiolabeled albumin was purified and analyzed by GFC using an $8 \times$ 300 mm, 200- $\AA$ Diol (catalog number DL06S053008WT; YMC) column and PBS as mobile phase. GFC-purified ${ }^{99 \mathrm{~m}} \mathrm{Tc}-\mathrm{HYNIC}-$ albumin (specific activity, $1.8 \times 10^{7} \mathrm{MBq} / \mathrm{mmol} ; 476 \mathrm{Ci} / \mathrm{mmol}$ ) was concentrated to $\approx 148 \mathrm{MBq} / \mathrm{mL}(4 \mathrm{mCi} / \mathrm{mL})$ using a 5,000 molecular-weight cutoff cartridge (Vivaspin).

\section{Quantification of Chemical Stability}

[99m Tc-MAS 3 ]-SDF-1 $\alpha$ was boiled for $5 \mathrm{~min}$ in PBS in the presence or absence of $1 \mathrm{mM}$ dithiothreitol and also incubated for $4 \mathrm{~h}$ at $37^{\circ} \mathrm{C}$ in $100 \%$ calf serum. Stability and transmetallation were quantified using GFC and the 60 - $\AA$ Diol column as described earlier. GFC molecular weight markers (Bio-Rad) were as follows: $\mathrm{M}_{1}=$ thyroglobulin (670 kDa, $\left.\mathrm{r}_{\mathrm{t}}=4.4 \mathrm{~min}\right), \mathrm{M}_{2}=\gamma$-globulin $(158 \mathrm{kDa}$, $\left.\mathrm{r}_{\mathrm{t}}=5.1 \mathrm{~min}\right), \mathrm{M}_{3}=$ ovalbumin $\left(44 \mathrm{kDa}, \mathrm{r}_{\mathrm{t}}=6.9 \mathrm{~min}\right), \mathrm{M}_{4}=$ myoglobin $\left(17 \mathrm{kDa}, \mathrm{r}_{\mathrm{t}}=8.0 \mathrm{~min}\right)$, and $\mathrm{M}_{5}=\operatorname{vitamin} \mathrm{B}_{12}(1.3 \mathrm{kDa}$, $\left.\mathrm{r}_{\mathrm{t}}=12.4 \mathrm{~min}\right)$.

\section{Adenoviral Expression of Transgenes and Isolation of Neonatal Cardiomyocytes}

Human prostate cancer cell line PC-3 was obtained from the American Type Culture Collection. Adenoviruses coexpressing CXCR4 and green fluorescent protein (GFP) or human bone morphogenetic protein-2 and GFP were prepared as described previously (25). Cells were transduced at a multiplicity of infection of 500:1 and incubated for $48 \mathrm{~h}$ at $37^{\circ} \mathrm{C}$, under humidified $5 \% \mathrm{CO}_{2}$, in RPMI 1640 medium (Mediatech Cellgro) supplemented with $10 \%$ fetal bovine serum (Gemini Bio-Products) and 5\% penicillin/ streptomycin (Cambrex Bioscience).

Spontaneously beating cardiomyocytes were prepared from 1- to 2-d-old Sprague-Dawley rat pups (Charles River Laboratories) using an isolation system (Neonatal Cardiomyocyte Isolation System; Worthington Biochemical). Cardiomyocytes were cultured in 96-well filter plates (model MSHAS4510; Millipore) at 20,000 cells per well in F-10 medium (Invitrogen) in the presence of $5 \%$ fetal calf serum and $10 \%$ horse serum, $100 \mathrm{U}$ of penicillin/ streptomycin per milliliter, and $2 \mathrm{mM} \mathrm{L-glutamine} \mathrm{over} 48 \mathrm{~h}$.

\section{High-Throughput Live Cell-Binding Assay}

To quantify absolute affinity and $\mathrm{B}_{\max }$ for the surface of living cells, a high-throughput homologous competition assay was used as described in detail previously (23). Briefly, cells were split onto 96-well filter plates (model MSHAS4510) and grown to 50\% confluence (approximately 40,000 cells per well) over $48 \mathrm{~h}$. The assay was performed at $4{ }^{\circ} \mathrm{C}$ to avoid internalization of the radioligand due to constitutive endocytosis. Cells were washed twice with ice-cold PBS or serum and incubated for $20 \mathrm{~min}$ at $4^{\circ} \mathrm{C}$ with $0.02 \mathrm{MBq}(0.5$ $\mu \mathrm{Ci}$ ) of radiotracer in the presence or absence of homologous cold 
compound. Cells were then washed 3 times with PBS or serum using a vacuum manifold (catalog number MSVMHTS00; Millipore), and the well contents were transferred directly to $12 \times 75 \mathrm{~mm}$ plastic tubes placed in $\gamma$-counter racks and counted on a 10-detector $\gamma$-counter (model 1470 Wallac Wizard; Perkin Elmer). Imaging (96-well plates) was performed using a $\gamma$-camera (Isocam Technologies) equipped with a $1.27-\mathrm{cm}(0.5$-in) sodium iodide crystal and a high-resolution ( $1 \mathrm{~mm})$, low-energy collimator.

\section{Animal Model Systems}

Animal studies were performed in accordance with approved Institutional Animal Care and Use Committee protocols. Male Sprague-Dawley inbred rats (200-250 gm) were anesthetized with a $50 \mathrm{mg} / \mathrm{kg}$ concentration of intraperitoneal pentobarbital, intubated, and mechanically ventilated with a rodent ventilator at 80 breaths/min using room air. After a left lateral thoracotomy, the left anterior descending artery was ligated for $30 \mathrm{~min}$ with 6.0 silk suture (26). MI was confirmed by visualization of myocardial blanching and ballooning distal to the point of ligation. The incision was then closed by suturing all 3 layers (bone, muscle, and skin), and excess air was evacuated with a 22-gauge angiocath (BD) to prevent pneumothorax. Rats were extubated when spontaneous breathing returned and received $0.5 \mathrm{~mL}$ of $0.5 \%$ bupivicaine analgesia for the next $48 \mathrm{~h}$ until used for radiotracer studies as described later. For the sham group, rats of comparable body weight and age underwent similar procedures, with the exception of left anterior descending ligation.

\section{Blood Activity Curves, Biodistribution, and Clearance}

A total of $37 \mathrm{MBq}(1 \mathrm{mCi})$ of ${ }^{99 \mathrm{~m}} \mathrm{Tc}-\mathrm{MAS}_{3}$ or [ ${ }^{99 \mathrm{~m}} \mathrm{Tc}-\mathrm{MAS}_{3}$ ]SDF- $1 \alpha$ in $200 \mu \mathrm{L}$ of saline was administered intravenously via the retroorbital sinus. Blood was collected at 0,1 , 2, 5, 10, 15, 30, 60, 90, and $120 \mathrm{~min}$ after injection from the tail vein using microcapillary tubes, weighed, and counted as described earlier. Curve fitting was performed using software (Prism, version 4.0a; GraphPad). For measurement of total-body retention and clearance at $2 \mathrm{~h}$ after injection, we ligated the ureters and urethra with silk sutures, removed the bladder en masse, and combined it with excreted urine and feces before measurement of radioactivity in a dose calibrator. The remaining carcass was also measured in a dose calibrator, then the heart, lungs, spleen, liver, kidneys, stomach, intestine, and brain were resected, washed twice in PBS, weighed, and counted as described earlier. In rats undergoing MI, the heart was separated into noninfarcted and infarcted tissue before quantitation. An additional cohort of rats was injected with $37 \mathrm{MBq}(1 \mathrm{mCi})$ of ${ }^{99 \mathrm{~m}} \mathrm{Tc}$-labeled albumin in $200 \mu \mathrm{L}$ of saline to measure perfusion. Statistical analysis was performed with an unpaired $t$ test using Prism.

\section{Confocal Fluorescence Microscopy}

In parallel with radiotracer experiments, an additional cohort of rats was sacrificed $24 \mathrm{~h}$ after surgery by sodium pentobarbital overdose, and hearts were excised and frozen on dry ice. Cryosections $(16 \mu \mathrm{m})$ were collected on slides (Superfrost Plus; Menzel), postfixed with $2 \%$ paraformaldehyde and $2 \%$ sucrose, and permeabilized with $0.3 \%$ Triton X-100 (Sigma). Sections were blocked in $2 \%$ BSA in PBS (blocking solution). Mouse anti-SDF-1 $\alpha$ monoclonal antibody (catalog number MAB350; R\&D Systems) or rabbit anti-CXCR4 polyclonal antibody (catalog number TP503; Torrey Pines Biolabs) was diluted 1:80 or 1:100, respectively, in blocking solution; incubated overnight at $4{ }^{\circ} \mathrm{C}$ with the specimen; and visualized using fluorophore-labeled goat anti-mouse IgG or goat anti-rabbit IgG secondary antibodies, respectively. F-actin was visualized with rhodamine phalloidin (catalog number R415; Invitrogen). Negative controls were incubated with nonimmune rabbit IgG (catalog number AB-105-C; R\&D Systems) and mouse IgG isotype control (catalog number MAB002; R\&D Systems). Nuclei were counterstained with 4'-6-diamidino-2-phenylindole (DAPI). Photomicrographs were captured on a Leica TCS-SP (ultraviolet) confocal microscope at the Mount Sinai School of Medicine Microscopy Shared Research Facility.

\section{RESULTS}

Radiolabeling and Purification of [ ${ }^{99 m}$ Tc-MAS $_{3}$ ]-SDF-1 $\alpha$

Using high-specific-activity, solid-phase preloaded $\left[{ }^{99 m}\right.$ Tc- $\left.\mathrm{MAS}_{3}\right]-\mathrm{NHS}, \mathrm{SDF}-1 \alpha$ was labeled under nonaqueous conditions (Fig. 1) and purified using GFC (Fig. 2), resulting in a radiotracer with more than $98 \%$ radiopurity and a minimum specific activity of $8.0 \times 10^{7} \mathrm{MBq} / \mathrm{mmol}(2,166$ $\mathrm{Ci} / \mathrm{mmol}$ ). For the initial ${ }^{99} \mathrm{mcO}_{4}{ }^{-}$, the average radiolabeling yield was $70 \%$ (range, $65 \%-75 \%$ ) for more than 20 separate labeling procedures. For [ $\left.{ }^{99 \mathrm{~m}} \mathrm{Tc}-\mathrm{MAS}_{3}\right]-\mathrm{NHS}$, radiolabeling yield was greater than $98 \%$ for more than 20 separate labeling procedures. Although the major peptide peak of recombinant SDF- $1 \alpha$ has a retention time $\left(r_{t}\right)$ of 9.6 min and was labeled efficiently, other minor peaks were labeled with varying efficiency (Fig. 2). The specific-activity calculation is based on the entire mass of SDF- $1 \alpha$ present in the labeling reaction and is thus likely an underestimate of the true specific activity. No attempt was made to identify which of the $9(1 \alpha, 8 \varepsilon$; Fig. 1) possible primary amines were labeled, although the low molar ratio of [ $\left.{ }^{99} \mathrm{~m}^{\mathrm{Tc}}-\mathrm{MAS}_{3}\right]-\mathrm{NHS}$ to $\mathrm{SDF}-1 \alpha(0.7: 1)$ ensured that, on average, fewer than 1 radioatom per molecule was incorporated. [ ${ }^{99} \mathrm{mTc}_{\mathrm{TAS}}$ ]SDF- $1 \alpha$ was readily separable from spontaneously hydrolyzed ${ }^{99 \mathrm{~m}} \mathrm{Tc}-\mathrm{MAS}_{3}$ at $\mathrm{r}_{\mathrm{t}}$ of $13.5 \mathrm{~min}$ (data not shown).

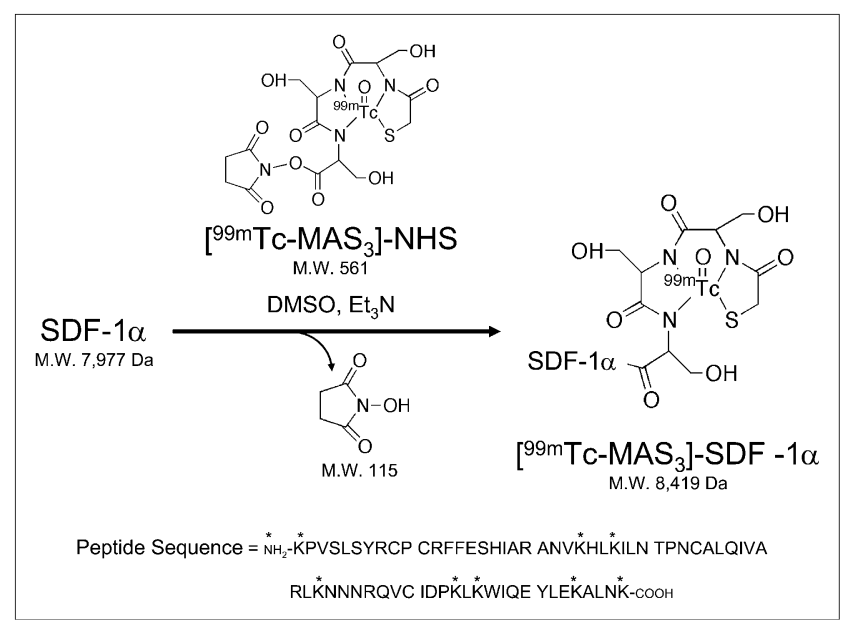

FIGURE 1. ${ }^{99 m}$ Tc-radiolabeling of SDF- $1 \alpha$. Solid-phase prelabeled [ ${ }^{99 m} \mathrm{Tc}_{\mathrm{MAS}}$ ]-NHS was conjugated covalently to recombinant SDF-1 $\alpha$ in DMSO in presence of base, releasing only NHS as byproduct. Primary amines available for conjugation are indicated by * in peptide sequence. 


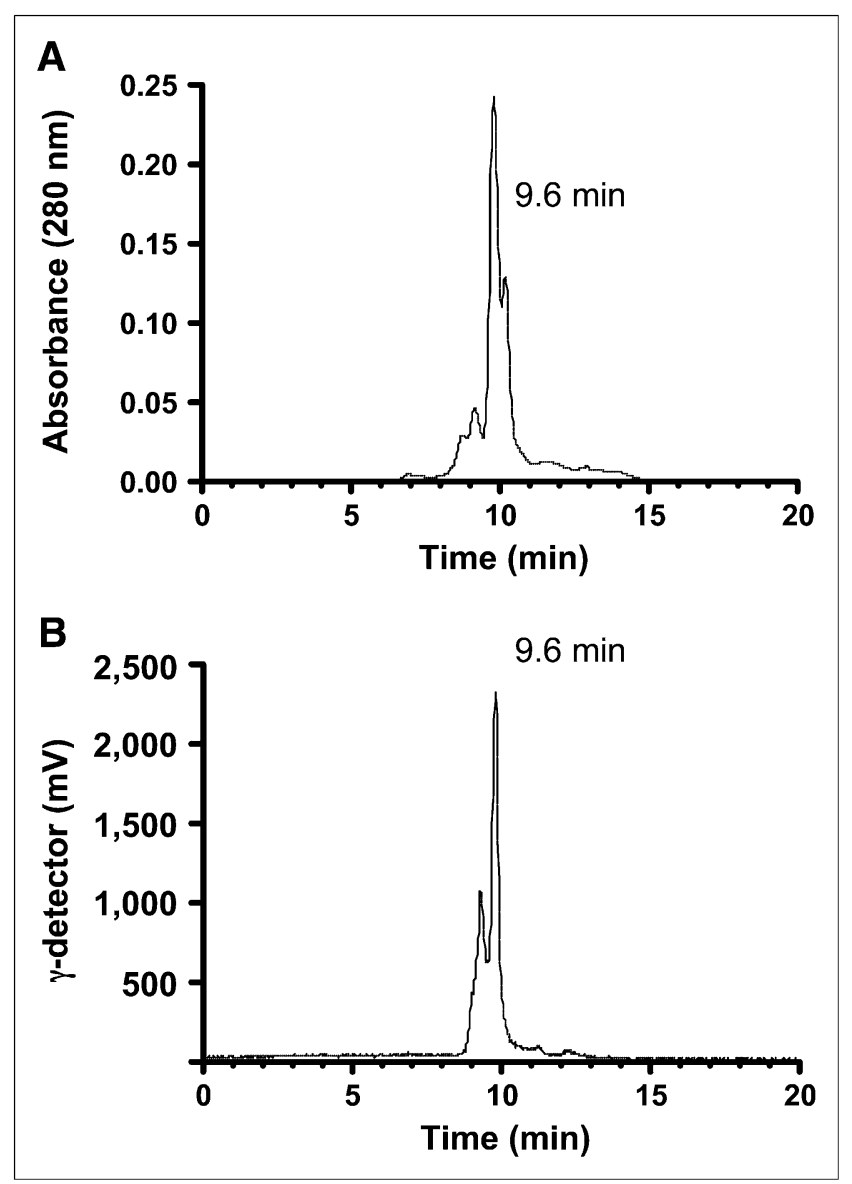

FIGURE 2. Purification and stability of $\left[{ }^{99 m} \mathrm{Tc}^{-M A S_{3}}\right]-\mathrm{SDF}-1 \alpha$. Purification of [ $\left.{ }^{99 \mathrm{~m}} \mathrm{Tc}_{\mathrm{C}}-\mathrm{MAS}_{3}\right]-\mathrm{SDF}-1 \alpha$ using GFC and simultaneous monitoring of $280-\mathrm{nm}$ absorbance (A) and $\gamma$-ray activity (B). Retention times of major peaks are also shown. Tracings are representative of 8 independent labeling reactions.

\section{Stability of [ $\left.{ }^{99 m} \mathrm{Tc}-\mathrm{MAS}_{3}\right]-\mathrm{SDF}-1 \alpha$}

Although one of the features of ${ }^{99 \mathrm{~m}} \mathrm{Tc}-\mathrm{MAS}_{3}$ complexes is high stability, and conjugation of the complex to SDF- $1 \alpha$ was designed to be covalent, we tested the stability of $\left[{ }^{99 \mathrm{~m}} \mathrm{Tc}-\right.$ $\mathrm{MAS}_{3}$ ]-SDF-1 $\alpha$ under various conditions. There was no evidence of complex dissociation after boiling for $5 \mathrm{~min}$ in the presence or absence of $1 \mathrm{mM}$ dithiothreitol and no evidence of transmetallation when incubated with $100 \%$ serum for $4 \mathrm{~h}$ at $37^{\circ} \mathrm{C}$. Quantitation of the chromatographs (data not shown) suggested that more than $98 \%$ of $\left[{ }^{99 m} \mathrm{Tc}-\right.$ $\left.\mathrm{MAS}_{3}\right]$-SDF- $1 \alpha$ remained intact under these conditions.

\section{Affinity and Specificity of [99mTc-MAS $\left.{ }_{3}\right]-S D F-1 \alpha$ for CXCR4 on Surface of Living Cells}

Using a previously described live cell homologous competition assay (23), we were able to characterize the affinity and specificity of [ $\left.{ }^{99 \mathrm{~m}} \mathrm{Tc}-\mathrm{MAS}_{3}\right]-\mathrm{SDF}-1 \alpha$ for CXCR 4 on the surface of living cells. First, nonactivated PC-3 human prostate cancer cells, which express low levels of CXCR4 mRNA (27) and no measurable protein, were transduced with an adenovirus coexpressing CXCR4 and GFP. GFP was used to confirm adenoviral transduction and to normalize levels of expression (data not shown). Negative controls included transduction with a similar adenovirus expressing bone morphogenetic protein-2 and GFP or untransduced cells. [99m Tc-MAS $\left.{ }_{3}\right]-S D F-1 \alpha$ exhibited high specificity for CXCR4, an affinity of $1.0 \pm 0.1 \mathrm{nM}$ (mean $\pm \mathrm{SD}$ ), and a $\mathrm{B}_{\max }$ of $2.6 \times 10^{5}$ binding sites per cell. Indeed, cells could be visualized in situ on the filter plates by $\gamma$-ray imaging (data not shown). Binding of [ $\left.{ }^{99 \mathrm{~m}} \mathrm{Tc}-\mathrm{MAS}_{3}\right]-\mathrm{SDF}-1 \alpha$ to neonatal rat cardiomyocytes exhibited a slightly lower affinity $(2.9 \pm$ $0.5 \mathrm{nM}$ ) than did adenovirus-overexpressed CXCR4 but exhibited a relatively high $\mathrm{B}_{\max }$ of $4.8 \times 10^{4}$ binding sites per cell. This measured affinity is consistent with the previously published value of $8.3 \pm 1.2 \mathrm{nM}$ for SDF- $1 \alpha$ binding to CXCR4 on human corneal fibroblasts (28). Results were nearly identical when the assay was performed in PBS (affinity of $2.9 \pm 0.5 \mathrm{nM}$ ) or $100 \%$ serum (affinity of $2.7 \pm$ $0.9 \mathrm{nM}$ ) with the same $B_{\max }$ of $4.8 \times 10^{4}$ binding sites per cell, suggesting that serum does not contain natural inhibitors of the binding process.

\section{Blood Half-Life, Biodistribution, and Clearance}

After intravenous injection, ${ }^{99 \mathrm{~m}} \mathrm{Tc}-\mathrm{MAS}_{3}$ alone exhibits an extremely short blood half-life of $5.0 \pm 1.0 \mathrm{~min}$ (Fig. 3A) and rapid renal clearance (data not shown), results consistent with previous reports (29). However, [ $\left.{ }^{99 m} \mathrm{Tc}-\mathrm{MAS}_{3}\right]-\mathrm{SDF}-$ $1 \alpha$ exhibits a prolonged blood half-life of $25.8 \pm 4.6 \mathrm{~min}$ (Fig. 3B). At $2 \mathrm{~h}$ after injection, $73.8 \% \pm 6.1 \%$ injected dose (\%ID) was found in excrement, primarily urine, with $26.2 \pm 6.1$ percentage injected dose (\%ID) remaining in the carcass (data not shown). Analysis of the major organs (Fig. 3C), except for the kidneys, the major site of excretion, revealed a relatively low uptake of less than $0.1 \% \mathrm{ID} / \mathrm{g}$. No brain uptake was measured, suggesting that $\left[{ }^{99 \mathrm{~m}} \mathrm{Tc}_{\mathrm{C}}-\mathrm{MAS}_{3}\right]-$ SDF- $1 \alpha$ does not cross the blood-brain barrier.

\section{Quantitation of Functional CXCR4 in Normal and Injured Myocardium}

To quantify the expression of CXCR4 in the setting of MI, a rat model of ischemia reperfusion was used as described in "Materials and Methods." Twenty-four hours after injury, and $2 \mathrm{~h}$ after intravenous injection of [ $\left.{ }^{99 \mathrm{~m}} \mathrm{Tc}-\mathrm{MAS}_{3}\right]-\mathrm{SDF}-$ $1 \alpha$, dramatic changes in CXCR4 expression were identified. As shown in Figure 4A, although normal myocardium from sham-operated rats and noninfarcted myocardium from MI rats had consistently low uptake of [99m Tc-MAS 3 -SDF$1 \alpha(0.11 \pm 0.02 \% \mathrm{ID} / \mathrm{g}$ and $0.11 \pm 0.1 \% \mathrm{ID} / \mathrm{g}$, respectively $)$, infarcted myocardium exhibited a 5-fold increase in CXCR4 expression $(0.57 \pm 0.04 \% \mathrm{ID} / \mathrm{g})$, with $P<0.0001$ for the comparison between infarcted and normal/noninfarcted tissue (Fig. 4A). Because MI can cause changes in local blood perfusion, the experiment was repeated using ${ }^{99 \mathrm{~m}} \mathrm{Tc}$-labeled albumin. As shown in Figure 4B, there was no statistical difference in ${ }^{99 \mathrm{~m}} \mathrm{Tc}$-labeled albumin uptake ${ }^{99 \mathrm{~m}} \mathrm{Tc}-\mathrm{HYNIC}-$ albumin) in noninfarcted and infarcted myocardium from the same animal.

Confocal fluorescence microscopy was then used to determine whether the quantitative changes seen using the 


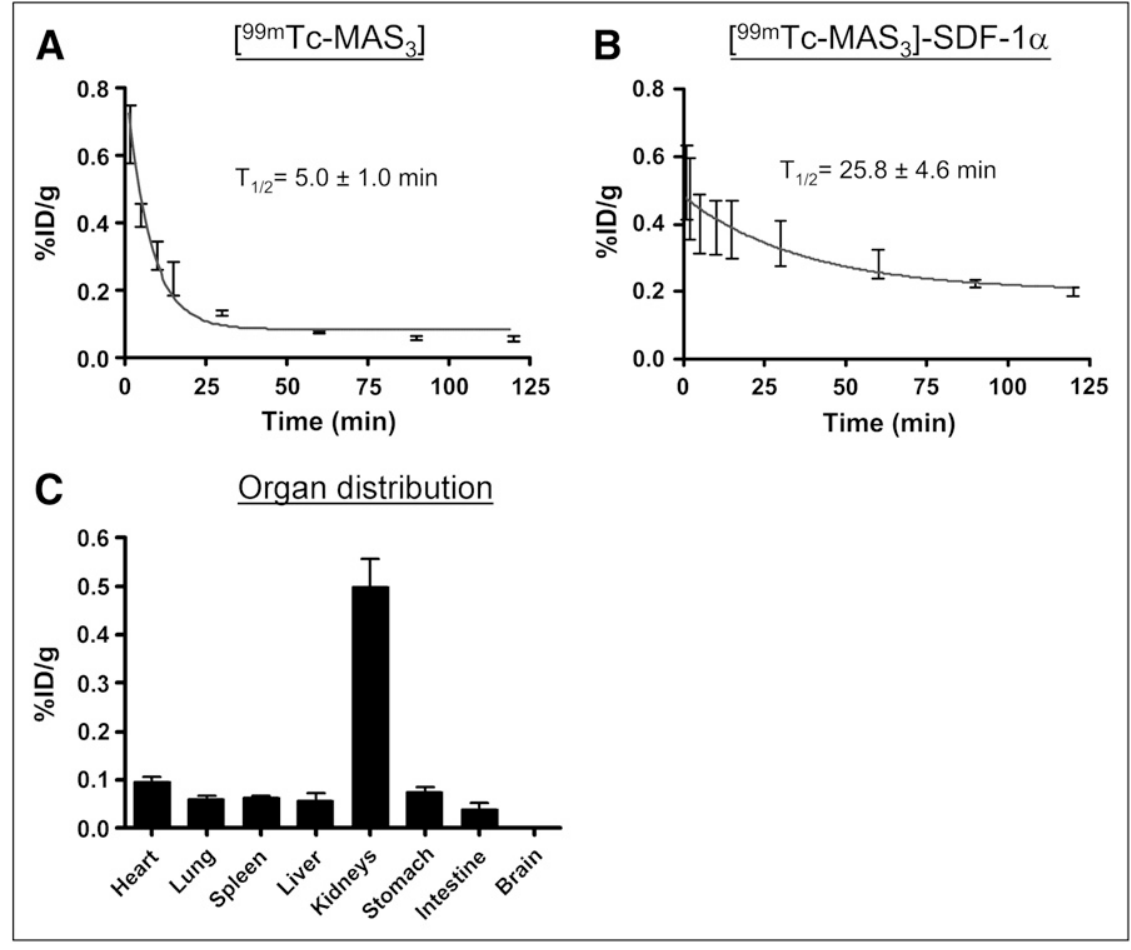

FIGURE 3. In vivo biodistribution and

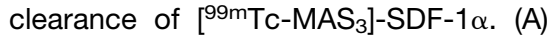
Blood activity curves (mean \pm SD) of

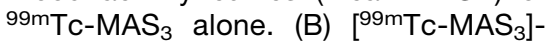
SDF- $1 \alpha$ after intravenous injection of 37 $\mathrm{MBq}(1 \mathrm{mCi})$ into sham-operated rats. Also shown are calculated half-lives. Results are from 3 independent experiments. (C) Total organ distribution (\%ID/g; mean $\pm \mathrm{SD}$ ) in the rats from Figure $3 \mathrm{~A}$ at $2 \mathrm{~h}$ after injection. $\left[{ }^{99 m} \mathrm{Tc}-\mathrm{MAS}_{3}\right]-\mathrm{SDF}-1 \alpha$ radiotracer were consistent with endogenous expression levels (30). As shown in Figure 4C, endogenous SDF-1 $\alpha$ (green) levels are increased in injured but not in noninjured or sham-operated myocardium, suggesting that SDF- $1 \alpha$ is part of the natural response to MI. Most important, endogenous CXCR4 expression (green) increases significantly after MI (Fig. 4D), along with SDF-1 $\alpha$ (red), confirming that $\left[{ }^{99 \mathrm{~m}} \mathrm{Tc}-\mathrm{MAS}_{3}\right]-\mathrm{SDF}-1 \alpha$ can be used to quantify CXCR4 levels in vivo.

\section{DISCUSSION}

Chemokines are a distinct class of inflammatory molecules that play a crucial role in a variety of developmental, physiologic, and pathologic processes including heart disease (31). The ability to quantify CXCR4 levels, noninvasively and over time, enables the mechanisms underlying their effects to be more successfully explored. In this study, we have opted to label the endogenous ligand for CXCR4, $\mathrm{SDF}-1 \alpha$, for use as a radiotracer. By using a previously described solid-phase prelabeling technique (23), we were able to achieve high specific activity while retaining bioactivity. [ ${ }^{99 \mathrm{~m}} \mathrm{Tc}^{-M A S_{3}}$ ]-SDF-1 $\alpha$ has a high affinity for CXCR4 and a high specificity on both overexpressing and endogenously expressing cells. Moreover, the radiotracer was remarkably stable under harsh conditions. In vivo, [ ${ }^{99 \mathrm{~m}} \mathrm{Tc}-$ $\left.\mathrm{MAS}_{3}\right]-\mathrm{SDF}-1 \alpha$ was cleared relatively quickly from the body via renal excretion, resulting in relatively low background tissue retention. Therefore, the in vivo quantification of CXCR4 levels using [ $\left.{ }^{99 m} \mathrm{Tc}^{\mathrm{m}}-\mathrm{MAS}_{3}\right]-\mathrm{SDF}-1 \alpha$ will likely significantly enhance studies to define the physiologic and pathophysiologic roles of SDF- $1 \alpha$ and CXCR4 in critical disease states such as MI and cancer.

In this study, we focused on the role of CXCR4 in MI. Infarcted myocardium expressed 5-fold higher levels of CXCR4 than did noninfarcted areas at $24 \mathrm{~h}$ after injury. We confirmed, using identically labeled albumin, that the increase in signal correlated specifically with CXCR4 and was not secondary to changes in myocardial perfusion. The reason CXCR4 (and SDF-1 $\alpha$ ) levels are markedly increased after ischemic injury is unknown but is the focus of intense investigation $(4,20)$. The development and experimental properties of $\left[{ }^{99 \mathrm{~m}} \mathrm{Tc}-\mathrm{MAS}_{3}\right]-\mathrm{SDF}-1 \alpha$ described in this study should assist future mechanistic studies by providing quantitation for the level and the kinetics of CXCR4 expression.

Numerous potential clinical uses for [ ${ }^{99 m} \mathrm{Tc}^{-M_{A} S_{3}}$ SDF- $1 \alpha$ as a SPECT radiotracer exist. First, it may be used to quantify the extent of injured myocardium in a patient after MI, without the high liver uptake associated with many currently implemented radiodiagnostic agents (3234). Second, it may be used to titrate drugs specific for CXCR4 by noninvasively probing receptor occupancy in the target organ of interest. Third, given that CXCR4 levels have been demonstrated to be increased in patients with heart failure (22), this radiotracer has the potential to determine whether CXCR4 levels differ in patients with cardiac dysfunction and thus stratify patients to prognosis and treatment regimen. Finally, $\left[{ }^{99 \mathrm{~m}} \mathrm{Tc}^{\left.-M_{A} S_{3}\right]-\mathrm{SDF}-1 \alpha \text { as }}\right.$ a SPECT radiotracer could be used during SC therapy to ensure that the local environment for cellular retention is amenable to engraftment. 
FIGURE 4. Quantitation of functional CXCR4 expression in myocardial infarction. Uptake (\%ID/g; mean \pm SEM) of [99mTc-MAS 3 ]-SDF-1 $\alpha$ (A) and $99 \mathrm{mTc}-$ labeled albumin (B) $24 \mathrm{~h}$ after sham operation (Sham) or ischemia reperfusioninduced myocardial infarction and $2 \mathrm{~h}$ after intravenous injection of $37 \mathrm{MBq}$ (1 $\mathrm{mCi}$ ) of radiotracer. Normal myocardium and infarcted myocardium from MI hearts were quantitated separately. Results are from 4 rats per group. (C) Confocal fluorescence microscopy of hearts from Figure 4A stained with mouse anti-SDF$1 \alpha$ antibody (green) and myocyte probe phalloidin (red). Nuclei are counterstained with DAPI (blue). (D) Confocal fluorescence microscopy of hearts from Figure 4A stained with anti-CXCR4 antibody (green) and anti-SDF- $1 \alpha$ antibody (red). Nuclei are counterstained with DAPI (blue).

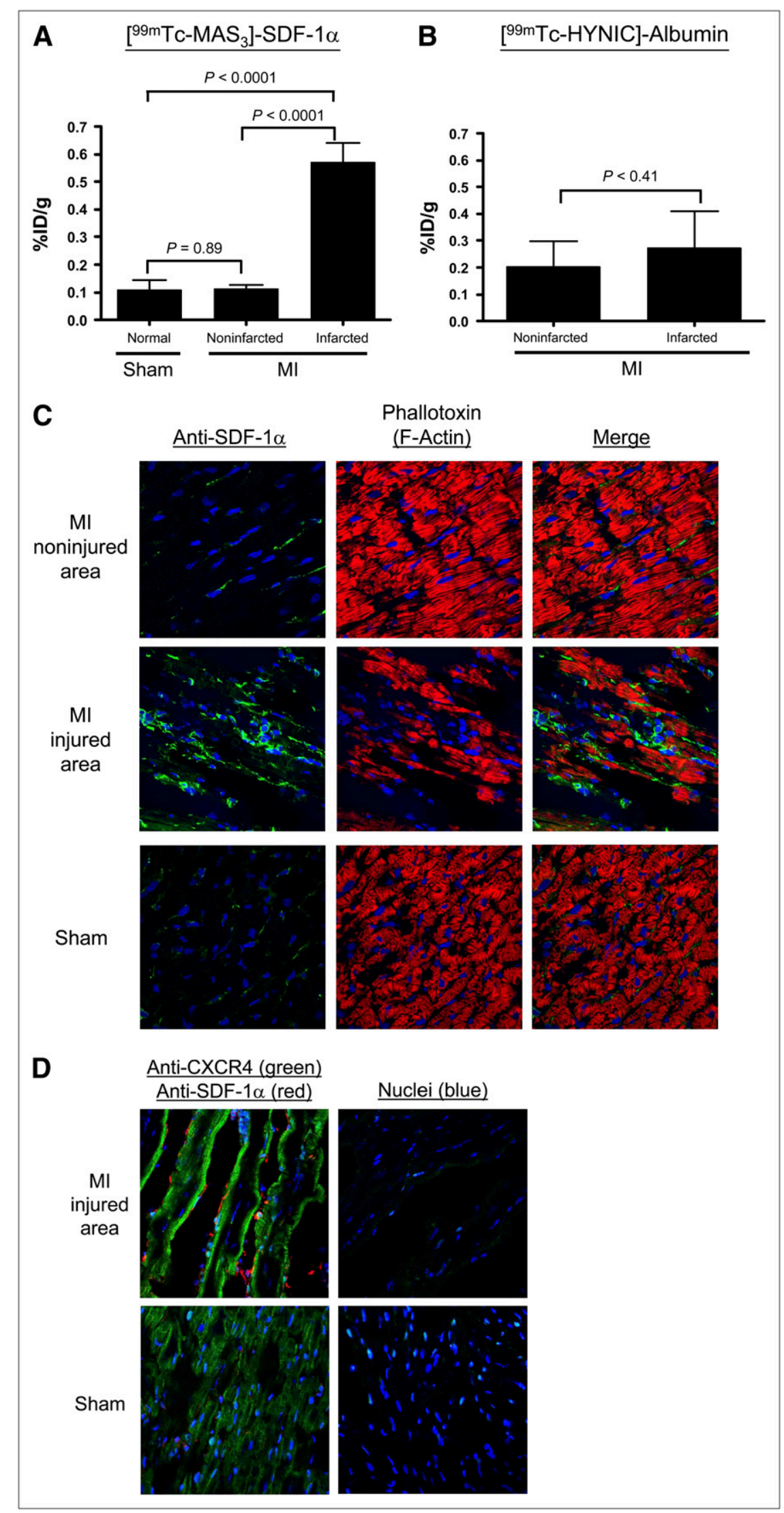

C

M

injured

area

D 


\section{CONCLUSION}

We describe the preparation of a high-specific-activity, ${ }^{99 \mathrm{~m}} \mathrm{Tc}$-labeled SDF- $1 \alpha$ radiotracer with high radiochemical purity and stability. [ $\left.{ }^{99 \mathrm{~m}} \mathrm{Tc}-\mathrm{MAS}_{3}\right]-\mathrm{SDF}-1 \alpha$ also possesses high affinity and specificity for its endogenous chemokine receptor, CXCR4, and can be used in vitro and in vivo as a noninvasive probe of CXCR4 expression levels. Using this radiotracer, we demonstrate that myocardial CXCR4 levels are increased 5-fold in myocardium subjected to ischemic injury, compared with levels in noninjured myocardium in the same heart. The potential clinical uses of the radiotracer in drug development and in patient management have been discussed.

\section{ACKNOWLEDGMENTS}

We thank Barbara L. Clough for editing and Eugenia Trabucchi and Alice Gugelmann for administrative assistance. This work was supported by NIH grants R01-CA115296, R01-HL-073458, and R01-HL-078691 and grants from the Lewis Family Fund and the Ellison Foundation.

\section{REFERENCES}

1. IUIS/WHO Subcommittee on Chemokine Nomenclature. Chemokine/chemokine receptor nomenclature. Cytokine. 2003;21:48-49.

2. Doitsidou M, Reichman-Fried M, Stebler J, et al. Guidance of primordial germ cell migration by the chemokine SDF-1. Cell. 2002;111:647-659.

3. Hatse S, Princen K, Liekens S, Vermeire K, De Clercq E, Schols D. Fluorescent CXCL12AF647 as a novel probe for nonradioactive CXCL12/CXCR4 cellular interaction studies. Cytometry A. 2004;61:178-188.

4. Yamaguchi J, Kusano KF, Masuo O, et al. Stromal cell-derived factor-1 effects on ex vivo expanded endothelial progenitor cell recruitment for ischemic neovascularization. Circulation. 2003;107:1322-1328.

5. Muller A, Homey B, Soto H, et al. Involvement of chemokine receptors in breast cancer metastasis. Nature. 2001;410:50-56.

6. Staller P, Sulitkova J, Lisztwan J, Moch H, Oakeley EJ, Krek W. Chemokine receptor CXCR4 downregulated by von Hippel-Lindau tumour suppressor pVHL. Nature. 2003;425:307-311.

7. Berger EA. Introduction: HIV co-receptors solve old questions and raise many new ones. Semin Immunol. 1998;10:165-168.

8. Nagaraju K. Update on immunopathogenesis in inflammatory myopathies. Curr Opin Rheumatol. 2001;13:461-468.

9. MacDermott RP. Chemokines in the inflammatory bowel diseases. J Clin Immunol. 1999;19:266-272.

10. Smith TK, Bader DM. Signals from both sides: control of cardiac development by the endocardium and epicardium. Semin Cell Dev Biol. 2007;18:84-89.

11. Weber C. Platelets and chemokines in atherosclerosis: partners in crime. Circ Res. 2005;96:612-616.

12. Pyo RT, Sui J, Dhume A, et al. CXCR4 modulates contractility in adult cardiac myocytes. J Mol Cell Cardiol. 2006;41:834-844.

13. Schober A, Zernecke A. Chemokines in vascular remodeling. Thromb Haemost. 2007;97:730-737.

14. Aukrust $\mathrm{P}$, Ueland T, Muller F, et al. Elevated circulating levels of C-C chemokines in patients with congestive heart failure. Circulation. 1998;97:1136-1143.
15. Nagasawa T, Tachibana K, Kishimoto T. A novel CXC chemokine PBSF/SDF-1 and its receptor CXCR4: their functions in development, hematopoiesis and HIV infection. Semin Immunol. 1998;10:179-185.

16. Behr TM, Wang X, Aiyar N, et al. Monocyte chemoattractant protein-1 is upregulated in rats with volume-overload congestive heart failure. Circulation. 2000;102:1315-1322.

17. Shioi T, Matsumori A, Kihara Y, et al. Increased expression of interleukin-1 beta and monocyte chemotactic and activating factor/monocyte chemoattractant protein-1 in the hypertrophied and failing heart with pressure overload. Circ Res. 1997;81:664-671.

18. Aukrust P, Damas JK, Gullestad L, Froland SS. Chemokines in myocardial failure: pathogenic importance and potential therapeutic targets. Clin Exp Immunol. 2001;124:343-345.

19. Abbott JD, Huang Y, Liu D, Hickey R, Krause DS, Giordano FJ. Stromal cellderived factor-1alpha plays a critical role in stem cell recruitment to the heart after myocardial infarction but is not sufficient to induce homing in the absence of injury. Circulation. 2004;110:3300-3305.

20. Askari AT, Unzek S, Popovic ZB, et al. Effect of stromal-cell-derived factor 1 on stem-cell homing and tissue regeneration in ischaemic cardiomyopathy. Lancet. 2003;362:697-703.

21. Zhang M, Mal N, Kiedrowski M, et al. SDF-1 expression by mesenchymal stem cells results in trophic support of cardiac myocytes after myocardial infarction. FASEB J. 2007;21:3197-3207.

22. Damas JK, Eiken HG, Oie E, et al. Myocardial expression of CC- and CXCchemokines and their receptors in human end-stage heart failure. Cardiovasc Res. 2000;47:778-787.

23. Misra P, Humblet V, Pannier N, Maison W, Frangioni JV. Production of multimeric prostate-specific membrane antigen small-molecule radiotracers using a solid-phase ${ }^{99 m}$ Tc preloading strategy. J Nucl Med. 2007;48:1379-1389.

24. Humblet V, Misra P, Frangioni JV. An HPLC/mass spectrometry platform for the development of multimodality contrast agents and targeted therapeutics: prostate-specific membrane antigen small molecule derivatives. Contrast Media Mol Imaging. 2006;1:196-211.

25. He TC, Zhou S, da Costa LT, Yu J, Kinzler KW, Vogelstein B. A simplified system for generating recombinant adenoviruses. Proc Natl Acad Sci USA. 1998; 95:2509-2514.

26. del Monte F, Lebeche D, Guerrero JL, et al. Abrogation of ventricular arrhythmias in a model of ischemia and reperfusion by targeting myocardial calcium cycling. Proc Natl Acad Sci USA. 2004;101:5622-5627.

27. Sun YX, Wang J, Shelburne CE, et al. Expression of CXCR4 and CXCL12 (SDF-1) in human prostate cancers (PCa) in vivo. J Cell Biochem. 2003;89:462473.

28. Bourcier T, Berbar T, Paquet $\mathrm{S}$, et al. Characterization and functionality of CXCR4 chemokine receptor and SDF-1 in human corneal fibroblasts. Mol Vis. 2003;9:96-102.

29. Rusckowski M, Qu T, Gupta S, Ley A, Hnatowich DJ. A comparison in monkeys of ${ }^{99 \mathrm{~m}} \mathrm{Tc}$ labeled to a peptide by 4 methods. J Nucl Med. 2001;42:1870-1877.

30. Czarnowska E, Gajerska-Dzieciatkowska M, Kusmierski K, et al. Expression of SDF-1-CXCR4 axis and an anti-remodelling effectiveness of foetal-liver stem cell transplantation in the infarcted rat heart. J Physiol Pharmacol. 2007;58:729744.

31. Viola A, Luster AD. Chemokines and their receptors: drug targets in immunity and inflammation. Annu Rev Pharmacol Toxicol. 2008;48: 171-197.

32. Kailasnath P, Sinusas AJ. Comparison of Tl-201 with Tc-99m-labeled myocardial perfusion agents: technical, physiologic, and clinical issues. J Nucl Cardiol. 2001;8:482-498.

33. Wackers FJ, Berman DS, Maddahi J, et al. Technetium-99m hexakis 2-methoxyisobutyl isonitrile: human biodistribution, dosimetry, safety, and preliminary comparison to thallium-201 for myocardial perfusion imaging. J Nucl Med. 1989;30: 301-311.

34. Okada RD, Glover D, Gaffney T, Williams S. Myocardial kinetics of technetium99m-hexakis-2-methoxy-2-methylpropyl-isonitrile. Circulation. 1988;77:491498. 